\section{THUMB SUCKING PREVENTION GLOVE EARNS} ACCREDITATION

Thumb sucking prevention tool Thumbsie has received Product Accreditation from the Oral Health Foundation.

Thumbsie works alongside dentists to help to stop children thumb sucking which can create dental problems such as overbite, misaligned teeth and even a malformed palette, which can lead to painful and prolonged dental treatment.

Experts at the Oral Health Foundation said that Thumbsie had included substantial anecdotal statements from the public verifying how this product had helped 'break the habit' of thumb/finger sucking in children.

Thumbsie was created in 2013 when Jo Bates (pictured) couldn't find an effective solution for her own daughter's thumb sucking problems. She made a fabric thumb guard which stopped her daughter sucking within five weeks. Seeing a gap in the market she launched her business and has been helping other families who are struggling with thumb and finger sucking ever since.

The Thumbsie is all the more relevant during the current COVID-19 pandemic as thumb sucking could help a virus get into the

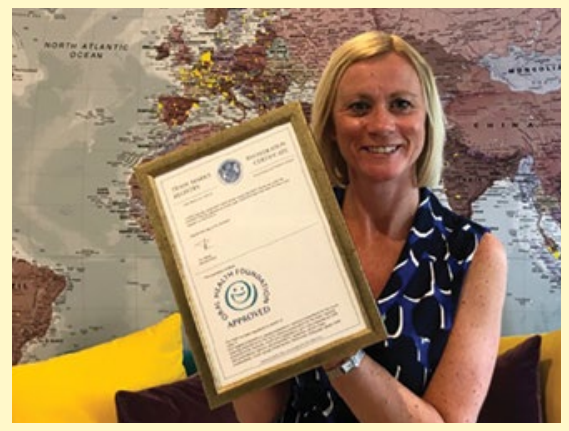

moist parts of the face (eyes, mouth, nose). A Thumbsie can make giving up faster and easy, reducing the chances of infection.

The Thumbsie thumb guard is available in over 40 child friendly fabric patterns to choose from which means that there will be something that everyone can enjoy wearing, whether it is unicorns or trucks.

The glove is secured around the wrist using Velcro. The glove comes in five different sizes; it has a simple measuring guide, which helps the guard to fit well on either hand. The product covers the thumb or finger and acts as a constant reminder when a child puts their thumb in their mouth.

To find out more about Thumbsie visit www.thumbsie.co.uk.

\title{
TOUCHLESS TREATMENT CONSENT
}

Whilst dental bodies across the UK offer an abundance of guidance on how to deliver high standards of care whilst keeping practices clean, you shouldn't have to worry about the quality of your consent.

'Paperless' and 'contactless' are the crucial solutions that Flynotes offers, and even more so with the introduction of Bring Your Own Device to dental practices.

After working with customers' feedback and in-house developers, Bring Your Own Device was developed to ensure that the risk of cross-contamination across technology is eliminated.

This gives the option for clinicians to go through the consent flow on a laptop or PC Then, once at the signing stage, the patient can sign the consent form using their own device by simply scanning a QR code and signing on their own touchscreen. This means that patients and clinicians are not required to share the same device at any point during the consent-gaining process.

Flynotes is a fully digital dental software that provides clinicians with the simplest and most effective way to deliver valid and informed consent in dentistry. Flynotes' system fits seamlessly into your clinical workflow. All of your consent forms are stored digitally and are easily viewed at any point in time, by both clinician and patient.

Additional to this, the robust documentation provides a full audit trail as every interaction with the platform is fully recorded, giving you peace of mind about what was discussed, which has been a popular feature amongst customers.

Flynotes was founded by dual dentist and doctor, Govin Murugachandran, who recognised the difficulties his colleagues and peers were facing concerning patient complaints and the risk of litigation. The aim was to support and help both clinicians and patients - which has been the ongoing narrative for this growing company.

Flynotes are currently offering a free trial of the software to help you become a touch-free practice. Contact hello@flynotes. co.uk or visit www.flynotes.co.uk to find out more.

\section{A SPECIAL APPTO COMMUNICATE WITH PATIENTS}

Now available for patients to download, allow your patients to complete medical history forms, update opt-ins and much more directly through the

Patient App!

iSmile is giving unrestricted access to all of its clients free for six

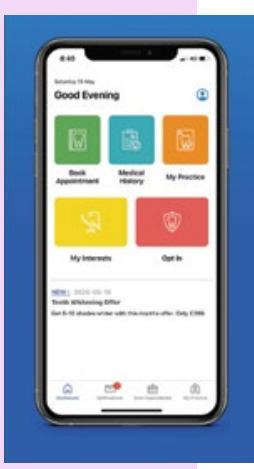
months and there is no limit on how many patients can download the app.

Call 08454681287 or send iSmile an email to info@ismiledental.co.uk and iSmile will set you up.

You will receive access to an online portal which you can use to send direct messages to your patients via the Patient App and keep them informed about important practice updates.

New feature updates are currently under development and will be released soon, allowing you to carry out remote triage appointments and give your patients an online booking facility at no extra cost.

PatientApp is free to use for six months. After that, the service fee is $£ 49$ +vat per month or you can uninstall without charge.

\section{MADE FROM PLANT-} BASED PLASTIC

The TePe GOOD range is made from plant-based plastic using renewable plantbased raw materials. New to the TePe GOOD range are the TePe GOOD Mini Flosser and TePe GOOD Tongue Cleaner in pink.

\section{The TePe GOOD Mini Flosser is} suitable for patients with narrow gaps between the teeth. The handle is made from wood fibres and sugar cane with a floss that is strong, thin and Teflon free. It is available in a 36-pack sustainable bag.

The TePe GOOD Tongue Cleaner is designed to remove bacteria on the tongue to improve oral health and help prevent halitosis. With three cleaning surfaces for a triple effect, the TePe GOOD tongue cleaner removes bacteria with one stroke. www.tepe.com/uk 